http://dx.doi.org/10.5800/GT-2014-5-1-0125

\title{
THE INSTITUTE OF THE EARTH’S CRUST MUSEUM TODAY
}

\author{
L. A. Ivanova \\ Institute of the Earth's Crust SB RAS, Irkutsk, Russia
}

\begin{abstract}
In the past five years, the Institute of the Earth's Crust Museum has considerably increased its exhibition space and the collection of objects. The Museum documents the history of the Institute since 1949. Its three rooms contain original artefacts, books and reports by prominent scientists and a rich variety of rocks collected by IEC staff, including a collection of new minerals discovered by IEC researchers and approved by the Commission for New Minerals Nomenclature and Classification (CNMNC) of the International Mineralogical Association. Displayed are a unique collection of kimberlites from Yakutia which was given to the Museum by D.I. Savrasov, a founder of the Kimberlites Museum in the city of Mirny, Republic of Sakha (Yakutia), a collection of hydrogenous minerals from many countries of the world which was given to the Museum by Dr. B.I. Pisarsky, a set of minerals collected by Dr. Yu.V. Komarov who founded the Museum and given to the Museum by his widow L.V. Komarova, and other sets of minerals. A special exhibition is devoted to the $100^{\text {th }}$ Anniversary of Prof. M.M. Odintsov, Corresponding Member of the USSR Academy of Sciences, who was a prominent Russian geologist, worked in Siberia and headed the IEC from 1954 to 1976. To commemorate the $90^{\text {th }}$ Anniversary of the Museum founder Dr. Yu.V. Komarov, the first museum room was renovated and now includes an exhibition devoted to researches of Dr. Yu.V. Komarov. A new display is a collection of minerals from Bulgaria. The Museum is regularly visited by high school and post graduate students to whom the museum objects and collections of minerals serve as useful physical materials in studies of geology and mineralogy, and in such cases the Institute of the Earth's Crust Museum operates as an educational outreach.
\end{abstract}

Key words: the Institute of the Earth’s Crust Museum, collection, display, exhibition.

Citation: Ivanova L.A. 2014. The Institute of the Earth’s Crust Museum Today. Geodynamics \& Tectonophysics 5 (1), 223-229. doi:10.5800/GT-2014-5-1-0125.

\section{МУЗЕЙ ИНСТИТУТА ЗЕМНОЙ КОРЫ СЕГОДНЯ}

\section{Л. А. Иванова}

\section{Институт земной коры СО РАН, Иркутск, Россия}

Аннотация: Музей Института земной коры за последнее пятилетие значительно расширил свои демонстрационные площади и обновил экспозиции. Основное направление - институт из прошлого (1949 г.) - в будущее... В трех выставочных залах экспонируются материалы, посвященные выдающимся ученым, внесшим огромный вклад в развитие сибирской науки, а также коллекции горных пород и минералов, собранные сотрудниками института. Представлены результаты научных исследований отдельных лабораторий. Демонстрируется коллекция новых минералов, открытых сотрудниками института и утвержденных Международной комиссией по новым минералам. Экспонируются: уникальная коллекция кимберлитов Якутии, подаренная музею Д.И. Саврасовым - основателем музея кимберлитов в г. Мирном; коллекция гидрогенных минералов различных регионов мира, переданная в дар музею д.г.-м.н. Б.И. Писарским; домашняя коллекция минералов, собранная основателем музея института д.г.-м.н. Ю.В. Комаровым, переданная в дар музею его вдовой, и ряд других коллекций. К 100-летию со дня рождения открыта экспозиция, посвященная жизни и деятельности выдающегося сибирского геолога, директора ИЗК с 1954 г. по 1976 г., 
чл.-корр. АН СССР, профессора М.М. Одинцова. К 90-летию со дня рождения основателя музея Ю.В. Комарова обновлен первый выставочный зал и открыта экспозиция, посвященная его жизни и деятельности. Открыта новая выставка «Минералы Болгарии». Все музейные коллекции служат наглядным материалом при проведении лекционных и практических занятий со студентами и аспирантами.

Ключевые слова: Музей Института земной коры, экспозиция, коллекция, выставка.

\section{1. ВВЕДЕНИЕ}

Решение о создании Геологического музея и фондов в Институте геологии ВСФ АН СССР, который в 1962 г. был переименован в Институт земной коры СО АН СССР, было принято в 1953 г. на заседании Президиума АН СССР при утверждении структуры института. Однако из-за отсутствия помещений ни музей, ни фонды созданы не были. Лишь в 1995 г. музей получил первое помещение, в котором по инициативе и при непосредственном участии д.г.-м.Н. профессора Ю.В. Комарова Геологический музей был размещен. Уже в 1998 г., когда в музейном зале начались систематические занятия со студентами Иркутского государственного технического университета, выставочная коллекция насчитывала более 800 образцов минералов, руд, горных пород, подаренных музею сотрудниками института. Экспозиция музея представляла собой небольшие тематические коллекции: щелочные комплексы Восточной Сибири, сибирские кимберлиты, цветные поделочные камни, породы и руды Слюдянского горно-рудного узла, базит-ультрабазитовые комплексы, а также минералы рудных месторождений Восточной Сибири и Монголии. На стендах было выставлено почти 700 значков, посвященных различным геологическим мероприятиям или событиям, а также Байкалу и Иркутску; экспонирована небольшая коллекция почтовых марок по геологической тематике; создан богатый фонд изданных карт геологического профиля, составленных сотрудниками института. На стенах музея выставлялись картины и другие экспонаты, подаренные ИЗК в связи с различными юбилеями.

\section{2. ДАНЬ ПАМЯТИ ВЕЛИКИМ УЧЕНЫМ}

16 октября 2009 г. к 60-летию Института земной коры был открыт новый музейный зал. В нем разместились фрагменты мемориальных кабинетов чл.-корр. АН СССР М.М. Одинцова (директор института в 1954-1976 гг.) и академика АН СССР Н.А. Логачева (директор института в 1976-1998 гг.); витрины и стенды, посвященные выдающимся ученым, много лет проработавшим в ИЗК и внесшим весомый вклад в развитие сибирской науки: директору-организатору
ИЗК (1949-1953 гг.), чл.-к. АН СССР, основателю сибирской школы неотектоники и геоморфологии Н.А. Флоренсову; заместителю директора института (19631967 гг.), профессору, д.ф.-м.н., основателю иркутской сейсмологической школы и организатору сети сейсмостанций Восточной Сибири А.А. Трескову; заместителю директора института (1967-1972 гг.), чл.-корр. АН СССР, основателю и руководителю сейсмологической научной школы В.П. Солоненко; заместителю директора института (1972-1995 гг.), чл-корр. РАН, главе сибирской школы гидрогеологов Е.В. Пиннекеру; информационные стенды каждой лаборатории, отражающие историю создания, основные направления научной деятельности и достижения данного коллектива сотрудников.

\section{3. МУЗЕЙ И ОСНОВНЫЕ НАУЧНЫЕ НАПРАВЛЕНИЯ ИНСТИТУТА ЗЕМНОЙ КОРЫ}

Экспозиция музея дала возможность получить полное представление об основных научных направлениях Института земной коры - комплексного научноисследовательского учреждения с оригинальным научным профилем, ознакомиться со структурой, лабораториями и уникальными результатами деятельности одного из научных учреждений страны в области геологии, геофизики, гидрогеологии и инженерной геологии.

Научная деятельность коллектива института по всем разрабатываемым проблемам достаточно плодотворна. Получены интересные, зачастую уникальные результаты, часть которых, несомненно являясь наследием института, экспонируется в музее.

С открытием нового музейного зала значительно расширилась тематика экспозиции. Геологический музей был переименован в Музей Института земной коры (рис. 1). Если основная цель деятельности Геологического музея заключалась в создании наглядной коллекции, то перед музеем института встал вопрос о сохранении историко-естественно-научного наследия будущему, потомкам и открытии этого наследия настоящему и современникам. Основное направление музейной экспозиции - Институт из прошлого (1949 г.) - в будущее... 


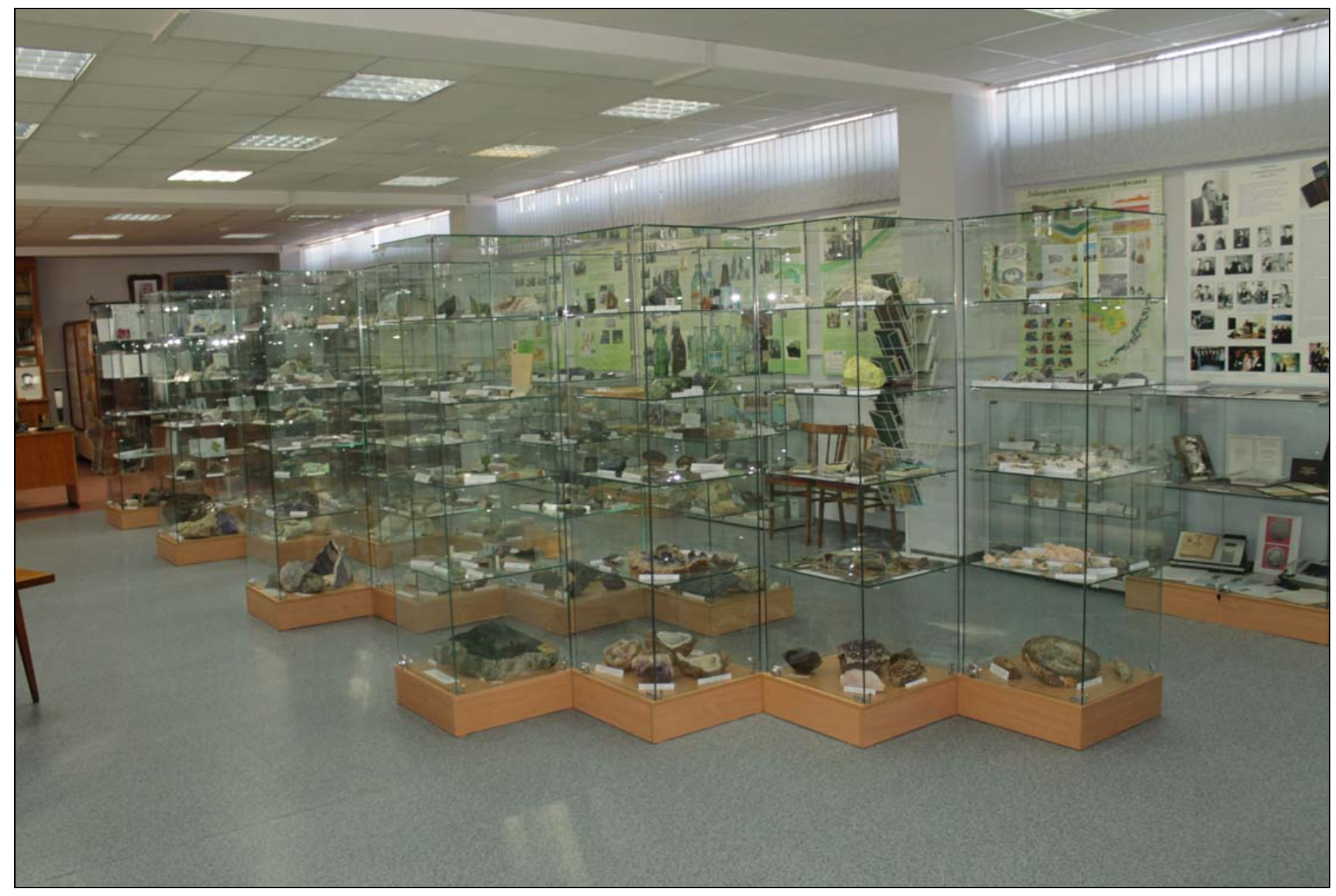

Рис. 1. Основной музейный зал сегодня.

Fig. 1. The main museum room.

\section{4. ИНСТИТУТ ИЗ ПРОШЛОГО (1949 Г.) - В БУДУЩЕЕ...}

В залах музея выставлены обновленные коллекции горных пород и минералов, собранные сотрудниками института. Среди них породы Мурунского, Тажеранского и других щелочных массивов, основные и ультраосновные породы и руды, золотоносные руды с видимым самородным золотом разных типов, черносланцевые золотоносные месторождения Сибири, Средней Азии, Монголии. Экспонируются образцы вольфрамитовых месторождений Забайкалья и Монголии, оловоносные руды касситерит-кварцевого типа с турмалином и пиритом Центрального Забайкалья и Дальнего Востока, молибденовые руды Бурятии и Читинской области. Значительно расширена экспозиция пород и руд Слюдянского горно-рудного узла, издавна служащего научным полигоном для петрологов, минералогов и геохимиков. Представлены коллекции ювелирных и поделочных камней Восточной Сибири и Монголии. Среди них разноокрашенные нефриты, лазуриты, чароиты, агаты и халцедоны. Оформлены витрины, в которых экспонируется коллекция минераль- ных вод Прибайкалья, исследованных в Институте земной коры. Представлены минеральные лечебностоловые и природные столовые бутилированные воды. Среди них пользующиеся популярностью «Иркутская», «Ангарская», «Братская», «Мальтинская», «Байкальская» и многие другие. Демонстрируются результаты инженерно-геологических исследований плотины Иркутской ГЭС после 50 лет эксплуатации. Выставлены образцы макротериофауны Южного Прибайкалья (поздний кайнозой), представляющие фрагменты костей мамонта, шерстистого носорога, бизона; ископаемой флоры каменноугольного и юрского периодов, представленные отложениями Якутской алмазоносной провинции (Северо-Восточный Тунгусский бассейн) и Иркутского угольного бассейна. Оформлена витрина представительной палеоген-неогеновой малакофауны Танхойской свиты Тункинской впадины Южного Прибайкалья.

Гордостью музейной экспозиции является выставка новых минералов, открытых А.А. Коневым, Л.3. Резницким, Е.В. Скляровым, З.Ф. Ущаповской, А.А. Кашаевым и другими сотрудниками института, утвер- 
жденных Комиссией по новым минералам, номенклатуре и классификации минералов Международной минералогической ассоциации (КНМНМ ММА). Экспонируются дипломы, каменный материал, фотографии, структуры 25 новых минеральных видов. Во многих случаях открытие новых минералов сопровождалось открытием новых минеральных серий - изоморфных рядов или твердых растворов, ранее не известных в природе и не синтезировавшихся. Часть новых минералов принадлежит к породообразующим или петрологически важным группам - пироксенам (наталиит), слюдам (хромфиллит), шпинелям (магнезиокулсонит), турмалинам (ванадиодравит, окси-хром-дравит). Нередко новые минералы отличаются необычными особенностями состава и структуры. Так, экспонирующиеся в музее сульфошпинели изоморфной серии калининит - флоренсовит - купрокалининит, открытые Л.3. Резницким, Е.В. Скляровым и 3.Ф. Ущаповской с коллегами, относятся к довольно редкому классу минералов - сульфидов со структурой обычных кислородных шпинелей, в которых вместо кислорода сера. Соединения хрома с серой в природе очень редки. Слюдянские минералы - первые находки хромовых сульфошпинелей в земных породах. Сульфошпинели десятки лет исследуются физикой и химией твердых тел, технологам они интересны важным сочетанием оптических, магнитных и диэлектрических свойств. Флоренсовит - пока единственный в минералогии пример изоморфизма хрома и сурьмы. Через несколько лет после открытия флоренсовит был синтезирован и оказался новым перспективным соединением как полупроводник.

Открытие Л.3. Резницким с соавторами ряда хромванадиевых турмалинов, последний из которых - хромо-алюмино-повондраит утвержден КНМНМ ММА в октябре 2013 г., привело к пересмотру общей классификации турмалинов и появлению группы окситурмалинов.

В названиях новых минеральных видов отражены имена видных исследователей Прибайкалья и Восточной Сибири. Так, наталиит назван в честь Наталии Васильевны Фроловой - выдающегося исследователя докембрия; калининит - в память о замечательном минералоге профессоре Павле Васильевиче Калинине, внесшем неоценимый вклад в изучение минералогии Южного Прибайкалья. В честь виднейших российских ученых-геологов, с именами которых связано становление академической науки в Восточной Сибири, Николая Александровича Флоренсова, Михаила Михайловича Одинцова, Льва Владимировича Таусона, Евгения Владимировича Павловского - получили свое название минералы флоренсовит, одинцовит, таусонит и павловскиит. По названию Института земной коры получил свое имя новый карбонат - земкорит, обнаруженный в кимберлите восточного тела трубки Удачная и изученный К.Н. Егоровым с коллегами. Отражается в названиях новых минералов и география При- байкалья: ольхонскит (остров Ольхон), олекминскит (река Олекма), тажеранит (Тажеранская степь), бираит (река Бирая), а также составы минеральных видов (батисивит - название дано по катионам, входящим в идеальную формулу (Ba, Ti, Si, V); хлормагалюминит; оксиванит - по компонентам идеальной формулы.

Выставка новых минералов в последнее время пополнилась за счет подобных исследований и открытий сотрудников Института геохимии СО РАН. Дипломы и образцы восьми новых минеральных видов переданы в дар музею А.Н. Сапожниковым, В.Е. Загорским, Н.В. Владыкиным с соавторами.

Подчеркивая тесную связь фундаментальных исследований и основанных на них прикладных разработок, в музее экспонируются результаты деятельности лабораторий в этом направлении. Среди таких разработок открытие И.В. Беловым и Н.Я. Волянюком в Западном Забайкалье месторождения вулканических стекол и туфов, пригодных для получения строительного материала - вспученного перлита. Производство бетона из перлита было принято Иркутским совнархозом для внедрения в народное хозяйство. За открытие месторождения и разработку возможностей использования вулканических стекол в качестве сырья для получения вспученного перлита И.В. Белову в 1960 г. присуждена малая золотая медаль ВДНХ. В 80-х годах $\mathrm{XX}$ в. на территориях Иркутской и Читинской областей Ю.В. Комаровым, А.В. Белоголовкиным, Э.Н. Копыловым открыты месторождения кремугитового сырья. Это был новый для Восточной Сибири строительный материал, применяемый как пористый заполнитель легких бетонов, получаемый по сухому способу из углеродсодержащих кремнисто-гидрослюдистых алевролитов и сланцев.

Уникальная экспозиция посвящена разнообразной продукции из безжелезистых волластонит-диопсидовых руд Слюдянского района Южного Прибайкалья. В экспозиции представлены волластонитовые и диопсидовые руды, а также авторское свидетельство на изобретение «Способ поиска волластонитовых горных пород», полученное В.Н. Вишняковым - первооткрывателем месторождения волластонита - в соавторстве с Е.И. Воробьевым, В.М. Новиковым, Л.З. Резницким, Е.П. Васильевым и А.Ф. Щербаковым. Диопсид и диопсидовые горные породы являются принципиально новым в мировой практике видом минерального сырья. Приоритет в изучении природного диопсида как полезного ископаемого принадлежит нашей стране. В технологическом плане диопсид имеет ряд несомненных достоинств, к которым относятся очень высокие диэлектрические характеристики при относительно невысокой температуре плавления, небольшие значения коэффициента термического расширения при высоких физико-механических свойствах, отсутствие полиморфных модификаций (стабильность в изделиях), химическая стойкость, широкая изоморфная емкость и др., чем определяется повышенный интерес к диопси- 
довым материалам. Экспонируются образцы керамических диэлектриков, тонкой и строительной керамики, образцы керамических пигментов на диопсидовой основе, керамические глазури, стекла, ситаллы, каменное литье, диопсидсодержащие материалы на основе вяжущих веществ.

Несомненным украшением экспозиции разноокрашенных нефритов Восточной Сибири является разработка В.Я. Медведева и Л.А. Ивановой «Способ обработки природных камней и изделий из них», предназначенная для улучшения декоративно-художественных качеств камнесамоцветного сырья, по своей окраске и механическим свойствам не отвечающих предъявляемым требованиям. Среди нефритов это табачные, зеленовато-табачные, буроватые, желтоватые нефриты, получившие подобные оттенки благодаря вторичным процессам, широко проявленным по краевым частям жил, вблизи трещин, а также на участках нефритоносных зон, подверженных катаклазу. Процесс облагораживания основан на изотермической выдержке образцов и изделий в восстановительной атмосфере при общем давлении 50-100 МПа и температуре 400$500{ }^{\circ} \mathrm{C}$. Способ позволяет за счет изменения вариантов количественного сочетания двух- и трехвалентного железа и других хромофоров получать ювелирные нефриты необходимых тонов нужной окраски и улучшать их механические свойства.

Не все результаты научных исследований могут быть представлены в виде коллекций. Достижения в области геотектоники, геофизики, сейсмологии, сейсмостойкого строительства, инженерной геологии, мерзлотоведения и ряда других разрабатываемых направлений представлены в музее в виде демонстрационных стендов, патентов, авторских свидетельств на изобретения.

Особенностью музейного собрания является мемориальность некоторых коллекций, связанных с именами выдающихся ученых, посвятивших свою жизнь исследованию минеральных богатств нашей страны. Среди них коллекции по щелочным массивам Прибайкалья и других регионов, составленные д.г.-м.н. А.А. Коневым - петрографом и минералогом, специализировавшимся в области щелочного магматизма Прибайкалья; коллекция гидрогенных минералов различных регионов мира, переданная в дар д.г.-м.н. Б.И. Писарским - специалистом в области региональной гидрогеологии и ресурсов подземных вод; уникальная коллекция кимберлитов Якутии, подаренная музею Д.И. Саврасовым - основателем единственного в мире Музея кимберлитов в п. Мирный.

Очень дорога музею памятная домашняя коллекция минералов, собранная его основателем д.г.-м.н. Ю.В. Комаровым - специалистом в области магматической геологии и металлогении, переданная в дар музею вдовой Юрия Васильевича - Любовью Всеволодовной. Коллекция представлена 75 экспонатами, среди которых прекрасная друза аметиста, кристаллы горного хрусталя, дымчатого кварца, мориона, аквамарина; агаты, халцедоны, сапфирины, сердолики, самородная сера, пейзажная яшма и яшмоиды; полированные образцы лазурита, офиокальцита и другие породы и минералы. Большой интерес вызывают каменные картины - работы Юрия Васильевича, выполненные им на мраморных пластинах разными минералами. Среди них «Байкальский полевой цветок», «Стрекоза», «Обезьянки», «Кораблик». Коллекция дополнена сувенирами и образцами, подаренными Юрию Васильевичу к памятным дням и юбилеям. Открытие выставки этой коллекции было приурочено ко Дню геолога в 2010 г.

В ноябре 2011 г. в рамках Всероссийской конференции, посвященной 100-летию со дня рождения Михаила Михайловича Одинцова - директора ИЗК с 1954 по 1976 г., член-корреспондента Академии наук СССР профессора, выдающегося сибирского геолога, одного из первооткрывателей сибирских алмазов - открыта экспозиция, посвященная его жизни и деятельности [Ivanova, 2011]. М.М. Одинцовым выделены территории Якутии, перспективные на обнаружение источников алмазов. Намечены перспективы алмазоносности юга Сибирской платформы и Присаянья. Экспозиция разворачивается на фоне коллекции кимберлитов Якутии и других регионов мира [Ivanova et al., 2013]. Демонстрируется макет кимберлитовой трубки Мир, открытой в июне 1955 г. - первого разрабатываемого месторождения алмазов в нашей стране.

Благодаря поддержке администрации института и программе «Поддержка музеев СО РАН», в музее за последнее пятилетие отремонтированы выставочные залы, закуплены витрины и оборудование, обновляются и создаются новые экспозиции. Музей Института земной коры в настоящее время значительно обновил свои демонстрационные площади.

В январе 2014 г. к 90-летию со дня рождения основателя музея д.г.-м.н. профессора, заслуженного деятеля науки Республики Бурятия Юрия Васильевича Комарова в капитально отремонтированном первом музейном зале открыта экспозиция, посвященная его жизни и деятельности (рис. 2). Оформлен фрагмент кабинета, где экспонируются рабочее место Юрия Васильевича в музее, его библиотека, созданные им картины из каменной крошки. На стене - портрет Юрия Васильевича, подаренный музею Любовь Всеволодовной Комаровой. Демонстрируются фотографии, полевые дневники и отчеты, экземпляры кандидатской и докторской диссертаций, монографии. Демонстрируется коллекция рабочих образцов Юрия Васильевича, положившая начало музейным экспозициям. Среди этих образцов золотоносные, оловоносные, вольфрамовые и молибденовые руды Забайкалья, Дальнего Востока, Монголии, железные руды Бурятии и Украины.

К юбилею Ю.В. Комарова приурочено открытие выставки - «Минералы Болгарии», где демонстриру- 


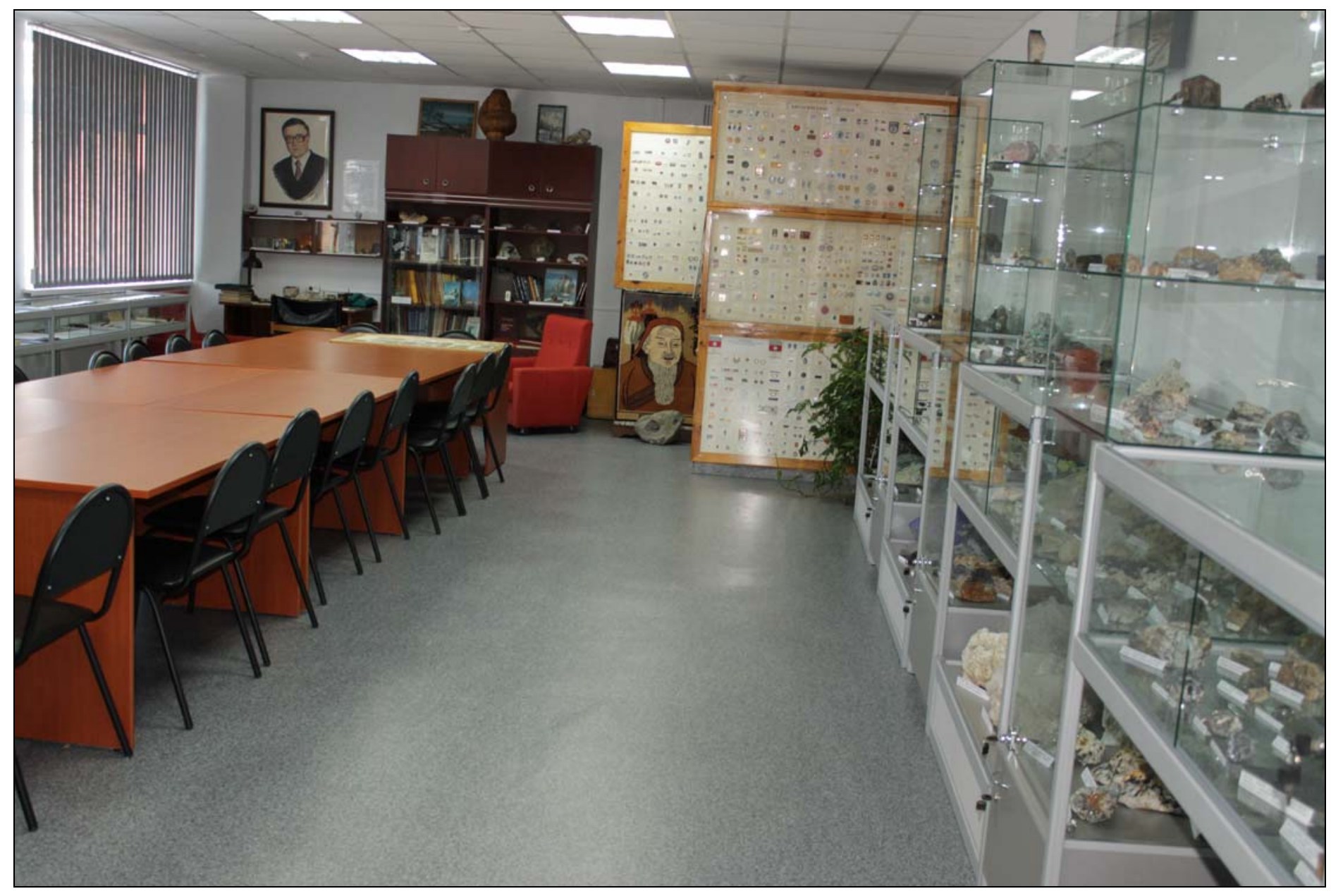

Рис. 2. Общий вид экспозиции, посвященной основателю музея - Ю.В. Комарову.

Fig. 2. The exhibition devoted to the Museum founder Dr. Yu.V. Komarov.

ются новые поступления - собранные сотрудниками образцы руд крупнейшего золоторудного месторождения Европы Челопеч, золоторудного месторождения Чала, железорудного месторождения Крумово, цеолитовая минерализация различных пород.

Все музейные коллекции служат наглядным материалом при проведении лекционных и практических занятий со студентами Иркутского государственного университета (ИГУ) и Иркутского государственного технического университета (ИрГТУ). Использование музея как аудитории для занятий значительно усиливает восприятие слушателями излагаемого материала, так как многие экспонируемые образцы принимают непосредственное участие в лекционном процессе. Благодаря расширенным и обновленным коллекциям появилась возможность наглядной демонстрации образцов в процессе чтения курса лекций «Природа окраски минералов» студентам кафедры геммологии Института недропользования ИрГТУ. Экспозиция результатов обработки природных камней и изделий из них способом, разработанным сотрудниками лаборатории петрологии, геохимии и рудогенеза, демонстри- рует возможности облагораживания некондиционного поделочного сырья на примере улучшения декоративно-художественных свойств нефрита и служит наглядным пособием в процессе проведения занятий курса лекций «Методы облагораживания ювелирных камней». Экспонируются исходные и облагороженные пластинки, кольца, браслеты, двухцветные образцы, гемма из Улан-Ходинского нефрита.

Студенты биолого-почвенного факультета ИГУ в курсе лекций «Основы палеоботаники» используют рабочие коллекции ископаемой флоры каменноугольного и юрского периодов.

Аспиранты Института земной коры с первого года обучения в курсе обязательных лекций ведущих научных сотрудников института получают возможность на примере экспозиций более детально ознакомиться с представляемыми научными направлениями. Пройдя по музейным залам, вникнув в историю развития существующих в институте в настоящее время профильных геологических отделов, осознав, что музей - это не только история, но и наша память, будущие сотрудники более ответственно ощущают себя в научном со- 
обществе института. Именно от них зависит сохранение преемственности, которая позволит вовлечь уже имеющиеся музейные коллекции и отдельные музейные образцы в новые экспозиции, так как одной из главных функций музея института является не только сохранение, но и дальнейшее пополнение коллекций, и формирование новых.

Музеем ведется популяризация геологических знаний среди населения и, прежде всего, среди школьников и студентов. Знакомство с музейными экспози- циями позволяет получить представление о комплексных исследованиях сотрудников института в области геологии, геофизики, гидрогеологии и инженерной геологии; осознать важность и необходимость этих исследований для развития и процветания нашего края.

Сотрудники музея благодарны всем, кто оказывает неоценимую помощь в решении возникающих проблем.

\section{5. ЛИТЕРАTУРA / REFERENCES}

Ivanova L.A., 2011. Mikhail M. Odintsov's exhibition in the museum of the Institute of the Earth’s Crust. Geodynamics \& Tectonophysics 2 (4), 430-437. http://dx.doi.org/10.5800/GT-2011-2-4-0055.

Ivanova L.A., Koshkarev D.A., Levi T.M., 2013. Mikhail M. Odintsov and diamond theme in the museum exposition of the Institute of the Earth's crust. Vestnik Irkutskoy gosudarstvennoy sel'skokhozyaystvennoy akademii 57 (1), 163-169 (in Russian) [Иванова Л.А., Кошкарев Д.А., Леви T.M. Михаил Михайлович Одинцов и алмазная тематика в экспозиции музея Института земной коры // Вестник ИрГСХА. 2013. Вып. 57. Ч. 1. С. 163-169].

Иванова Лариса Александровна, канд. геол.-мин. наук., с.н.с., научный руководитель Музея ИЗК СО РАН Институт земной коры СО РАН 664033, Иркутск, ул. Лермонтова, 128, Россия \e-mail: liva@crust.irk.ru

Ivanova Larisa A., Candidate of Geology and Mineralogy, Senior Researcher Scientific Supervisor of the Museum of the Institute of the Earth's Crust Institute of the Earth's Crust SB RAS 128 Lermontov street, Irkutsk 664033, Russia 凶e-mail: liva@crust.irk.ru 